\title{
Asthma from childhood at age 21: the patient and his disease
}

\author{
A J MARTIN, L I LANDAU, P D PHELAN
}

\begin{abstract}
Information was obtained from 336 21-year-olds who had begun wheezing before the age of 7 about their knowledge of asthma and its effect on their current life style. Twothirds of the subjects were still symptomatic. A control group of 62 subjects was available for comparison.

Knowledge about asthma was poor, particularly among those with less troublesome symptoms. Half of those with frequent episodic asthma and one-third with persistent asthma did not regard excess use of bronchodilator aerosols as potentially dangerous. Over three-quarters of those with frequent episodic asthma and two-fifths of those with persistent asthma were not receiving adequate treatment. One-third of those with persistent asthma were missing substantial time from work because of respiratory illness, and a similar proportion were restricting sporting activities. The incidence of smoking was disturbingly high in all asthma groups. The higher the number of cigarettes ever smoked and the higher the current tobacco consumption the less satisfactory was the progress of asthma. Both cigarette smoking and severity of asthma contributed to chronic production of sputum.

Children and teenagers with asthma should be educated to seek more appropriate medical help and thereby reduce morbidity.
\end{abstract}

\section{Introduction}

The ability of wheezing subjects to understand asthma is important in self-management and seeking appropriate care and treatment. Few published reports assess subjects' understanding of their asthma, and it has been suggested that asthma often goes unrecognised and is therefore both underdiagnosed and undertreated. ${ }^{12}$ Asthma may interfere with enjoyment of normal life styles: exercise-induced bronchoconstriction is common. Children, particularly those with chronic asthma, may miss a considerable amount of schooling, with possible effects on educational attainment and subsequent employment. ${ }^{3-7}$ Surprisingly, little information is available on the effects of asthma on physical activities and employment in early adult life.

Respiratory illness in children may be an important determinant of adult chronic obstructive lung disease. ${ }^{8-10}$ Previous studies, however, have not distinguished clearly between childhood respiratory disease associated with wheezing, which is almost certainly asthma, and true infective bronchitis. The rate of decline of lung function in adults with chronic obstructive lung disease is related to both smoking and underlying bronchial reactivity. ${ }^{11} 12$ No studies have related smoking and symptoms of chronic bronchitis in young adults who had a history of wheezing in childhood.

Williams and McNicol prospectively studied a randomly selected group of children who had wheezed during the first seven years of life and in parallel a randomly selected control population. ${ }^{13}$ We reviewed this group of subjects at 21 years of

Department of Thoracic Medicine, Royal Children's Hospital, Melbourne, Australia

A J MARTIN, MRCP, research fellow

L I LANDAU, MD, FRACP, deputy director of department

P D PHELAN, MD, FRACP, director of department age, ${ }^{14}$ and now report the findings relevant to the patients' understanding of asthma, its effect on life style and appropriateness of treatment.

\section{Subjects and methods}

The subjects were in a representative group of asthmatic children and a control group, randomly selected, from a single age stratum of 30000 Melbourne schoolchildren in 1964. From a total of 401 children, 371 had attended for detailed study at 7 years of age in 1964 . In 1967-8 a further 83 children with severe asthma were selected at random from the same age stratum. These children, together with 315 of the original 371, were seen at 10 and 14 years of age. All the children from the original study plus the 83 from the parallel study were followed up at 21 years of age : 342 attended for detailed study, 50 answered a questionnaire by telephone, and 16 replied to a postal questionnaire. Based on that review ${ }^{14}$ the following four grades of wheezing subjects were defined: grade $\mathrm{W}$, subjects with a history of wheezing during childhood or adolescence but no episodes in the three years before review at 21 years of age; grade $\mathrm{X}$, subjects who had wheezed within three years, but not within three months of interview or examination at 21 years; grade $\mathrm{Y}$, subjects who had wheezed within three months of interview or examination at 21 years of age and whose wheezing was neither very frequent nor persistent; and grade $Z$, subjects with a current history of frequent (once a week or more) or persistent wheezing during the past year.

For this study subjects were asked specific questions, not about their own asthma but about asthma in general. They were asked which of four conditions-namely, heart disease, kidney disease, hay fever, and eczema-were commonly associated with asthma. They were next given the choice of three factors-colds or throat infections; pollens, dust, or feathers; and emotional upsets-and asked if any or all were known provoking agents of acute wheezing episodes. They were also asked about long-term effects of asthma and about drugs used in its management.

Details of pharmacological treatment were recorded at 21 years. Appropriate treatment for subjects in grade W was no treatment; for subjects in grade $\mathrm{X}$ bronchodilators used only during acute wheezing episodes; for subjects in grade $\mathrm{Y}$ regular bronchodilators, disodium cromoglycate with intermittent or regular bronchodilators, or inhaled corticosteroids with regular bronchodilators; and for subjects in grade $\mathrm{Z}$ regular bronchodilators alone or with, if necessary, either long-term inhaled corticosteroids or disodium cromoglycate. Short-term or longterm oral corticosteroids may have been used.

Dynamic lung volumes were recorded with a nine-litre water-filled spirometer (Godart) and corrected to body temperature and saturated water-vapour pressure. Standard exercise tests were performed according to the usual protocol, ${ }^{15}{ }^{16}$ with a positive response being a fall in peak expiratory flow rate after exercise greater than $16.6 \%$ (control mean $+2 \mathrm{SD}$ ).

Chronic bronchitis was defined symptomatically according to the British Medical Research Council protocol. ${ }^{17}$

\section{Results}

Table I gives the responses to questions dealing with the subjects understanding of asthma and its treatment. Only those with chronic asthma had an adequate knowledge of asthma, its associated diseases, provoking factors, and treatment.

Current medical care was unsatisfactory. Twenty per cent of subjects in grade $\mathrm{Z}$ and $49 \%$ of those in grade $\mathrm{Y}$ were receiving no medical care. Only a quarter of the subjects in grade $Z$ were under the care of a specialist physician. Seventy-nine per cent of grade $Y$ and $41^{\circ}$ of grade $\mathrm{Z}$ subjects were taking inappropriate medications.

Asthma considerably affected the choice of occupation of $22 \%$ of subjects in grade $Z$. Prospective employers of a quarter of the subjects in grade $\mathrm{Z}$ and one in 10 of those in grade $\mathrm{Y}$ were influenced by a 
TABLE I-Percentages of subjects in control group and four asthma grades according to answers to questions assessing their knowledge of asthma

\begin{tabular}{|c|c|c|c|c|c|}
\hline & \multirow{2}{*}{ Control } & \multicolumn{4}{|c|}{ Asthma grades } \\
\hline & & w & $\mathrm{x}$ & $\mathbf{Y}$ & $\mathbf{Z}$ \\
\hline $\begin{array}{l}\text { Do not think they have a good } \\
\text { understanding of asthma } \\
\text { Did not know associated diseases } \\
\text { Did not know at least two provoking }\end{array}$ & $\begin{array}{l}49 \\
38\end{array}$ & $\begin{array}{l}47 \\
35\end{array}$ & $\begin{array}{l}40 \\
22\end{array}$ & $\begin{array}{l}31 \\
22\end{array}$ & $\begin{array}{l}20 \\
15\end{array}$ \\
\hline $\begin{array}{l}\text { factors } \ldots \\
\text { Thought lung damage unlikely } \\
\text { Regarded excess use of broncho- } \\
\text { dilator aerosol as potentially }\end{array}$ & $\begin{array}{l}63 \\
32\end{array}$ & $\begin{array}{l}55 \\
28\end{array}$ & $\begin{array}{l}37 \\
42\end{array}$ & $\begin{array}{l}37 \\
44\end{array}$ & $\begin{array}{l}23 \\
60\end{array}$ \\
\hline $\begin{array}{l}\text { dangerous } \\
\text { Believed disodium cromoglycate } \\
\text { should be used long term (total No } \\
\text { of subjects who had used the drug) }\end{array}$ & 25 & $43(7)$ & $29(7)$ & $33(36)$ & $80(46)$ \\
\hline
\end{tabular}

history of asthma. There was no significant difference between controls and any asthma grade in the number of changes in employment. Thirty-five per cent of subjects in grade $Z$ had missed more than two weeks from work in the preceding two years as a result of respiratory illness, and $36 \%$ had problems in obtaining life insurance policies. Equal proportions of controls and subjects with asthma had undertaken courses in further education after leaving school.

Fifteen per cent of grade X subjects, $20 \%$ of grade $\mathrm{Y}$, and $34 \%$ of grade $\mathrm{Z}$ were restricting their sporting and general physical activities that had been associated with wheezing. There was a strong correlation between a positive response to the exercise test and restriction of physical activities $(\mathrm{p}<0.001)$ (table II). Sixty-four per cent of those with a positive response to the exercise test gave a history of exerciseinduced asthma, but $34 \%$ of those with a negative response also gave such a history.

TABLE II-Percentages of subjects who were restricting physical activities and TABLE II-Percentages of subjects who were restricting physical activities and
who had a history of exercise-induced ast hma in relation to findings of a standardised exercise test

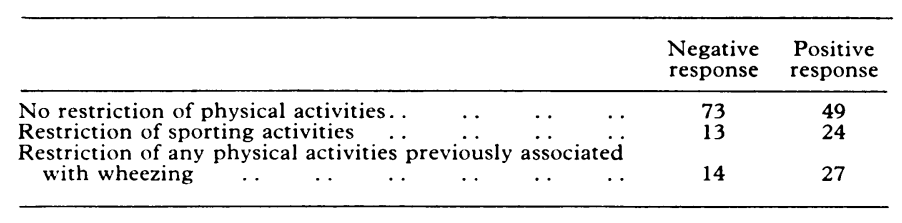

$\varkappa^{2}=1646 ; p \cdot 0 \cdot 001$.

Table III shows the patterns of smoking in the controls and subjects in the four asthma grades. No significant difference was found between the groups, though there was a trend for smoking to be most frequent in those with the most severe asthma. Positive correlations between change in asthma grade between 14 and 21 years and number of packyears (Spearman correlation: rho $0.116 ; p<0.003$ ) and current smoking habits (rho $0.109 ; \mathrm{p}<0.05$ ) were significant. The higher the number of cigarettes smoked and higher the current tobacco consumption the poorer the progress of the asthma.

Fifty-one per cent of the grade $\mathrm{X}$ subjects, $54 \%$ of grade $\mathrm{Y}$, and $45 \%$ of grade $Z$ had an intermittent or persistent cough compared with $24 \%$ of the controls, a significant difference $\left(x^{2}\right.$ test : $\left.p<0.01\right)$. Only subjects in grade $Z$, however, had a higher incidence than controls of symptomatic chronic bronchitis $(44 \%$ as against $16 \% ; \mathrm{p}<0.001)$. Analysis of variance of the effects of asthma grades and smoking on chronic production of sputum showed that degrees of asthma and smoking habits contributed to the variation in chronic production. The effect of clinical asthma $(\mathrm{p}<0.0001,14 \%$ owing to this factor) was greater than and independent of current smoking

TABLE III-Cigarette consumption in control group and four asthma grades. Figures are percentages of subjects

\begin{tabular}{lllrrrrr}
\hline & & & & \multicolumn{4}{c}{ Control } \\
\cline { 5 - 8 } & & & & W & X & Y & Z \\
\hline Non-smoker & $\ldots$ &. & 60 & 57 & 54 & 52 & 48 \\
Less than five a day & $\cdots$ &. & 9 & 10 & 7 & 9 & 6 \\
Five or more a day &. &. & 31 & 33 & 39 & 39 & 46 \\
\hline
\end{tabular}

habits ( $p<0.009,3 \%$ owing to this factor). The character of productive cough correlated with forced expiratory volume in one second $(p<0.001)$ forced expiratory flow between 25 and $75 \%$ vital capacity $(p<0.01)$. There was no significant difference between smokers and non-smokers in the control subjects and four asthma grades in measurements of pulmonary function.

\section{Discussion}

These results indicate that many young adults with asthma which began in childhood have poor understanding of the disease, are unaware of the potential risks of overusage of bronchodilator aerosols, have inadequate treatment, restrict their physical activities, and are missing substantial amounts of time from work. Furthermore, the high prevalence of smoking is worrying in a group of subjects with increased bronchial reactivity. Though beta ${ }_{2}$-adrenergic drugs are much less cardiotoxic than earlier inhaled sympathomimetics, ${ }^{18}$ that many subjects did not regard excess use as possibly dangerous is of particular concern.

Many of the subjects with continuing asthma were not making appropriate use of medical facilities in the community. Though the assessment of appropriateness of treatment was subjective, it seemed clear that many young adults with continuing asthma were being undertreated. Treatment of this same group of subjects at age 14 was inadequate. ${ }^{1}$ How much the substantial morbidity in subjects with persistent asthma (grade $Z$ ) could have been reduced by appropriate treatment is unknown. Exerciseinduced asthma in particular can often be prevented. Only four subjects had been under our medical care and the conditions under which the study had been conducted prevented us from interfering with medical treatment at the earlier stages of review.

In 1945 Flensborg commented that 39 of 116 subjects aged over 15 had chosen an occupation because of their asthma, ${ }^{3}$ a finding similar to ours. Treatment for asthma has improved since 1945, but the life style of affected subjects does not seem to be altered.

We found that equal proportions of each asthmatic grade and controls continued in further education after leaving school. Some studies have reported higher than expected levels of education attainment among children with asthma, ${ }^{56}$ whereas others have not found this association. ${ }^{4} 7$ These findings may have been influenced by social-class distribution in the groups studied. There were no significant socioeconomic differences between the control and asthmatic groups in our study. ${ }^{19}$

One-third of subjects with a negative response to the exercise test gave a positive history of exercise-induced asthma, and onethird with a positive response to the exercise test gave a negative history of exercise-induced asthma, findings similar to those reported before. ${ }^{20}$ Though the association between a history of exercise-induced asthma and a positive response to the exercise test is significant, a history of exercise-induced asthma or a positive response to the exercise test is not a reliable predictor of the degree of restriction of activities.

We could not show a measurable effect of smoking on pulmonary function indices but the progress of asthma was poorer among smokers than non-smokers. The relatively young age of our subjects may explain our failure to show abnormalities of pulmonary function; though these may occur after a relatively short period of smoking, they may be extremely variable..$^{21-23}$

The prevalence of productive cough was significant in those with continuing wheezing to 21 years but only those with very frequent or persistent wheezing at 21 years had a higher prevalence of symptomatic chronic bronchitis. It has been pointed out that clinical definitions of chronic bronchitis are not completely satisfactory because they are not based on pathological criteria, and subjects with asthma produce sputum without necessarily having the pathological changes of chronic bronchitis. ${ }^{24}$ The study did show that degree of asthma contributed more to the pattern of productive cough than did smoking. The interrelations of smoking, asthma, and chronic production of 
sputum and the genesis of adult chronic obstructive lung disease are complex. A steeper rate of decline in forced expiratory volume in one second has been shown in those smokers with a history of childhood respiratory symptoms or evidence of bronchoreactivity. ${ }^{81112}$ The subjects in this study may be at increased risk of developing chronic obstructive lung disease because of their asthma and smoking habits. Subjects in grade W may not be risk free, as $60 \%$ of them continued to show bronchial hyperreactivity though many had been wheeze free for 10 years or more. ${ }^{16}$

This study emphasises the need for better education of children and teenagers with asthma in the hope that as young adults they will seek more appropriate medical care and so reduce the morbidity from their disease. Further, education may reduce the incidence of smoking and hopefully thereby reduce the possible risk of their developing chronic obstructive lung disease in later life.

This study was supported by grants from the National Health and Medical Research Council and the Asthma Foundation of Victoria.

\section{References}

1 McNicol KN, Williams HE. Spectrum of asthma in children-I, clinical and physiological components. $\mathrm{Br}$ Med $\mathcal{F} 1973$;iv:7-11.

2 Speight ANP. Is childhood asthma being underdiagnosed and undertreated ? $\mathrm{Br}$ Med $\mathcal{F} 1978$;ii:331-2.

${ }^{3}$ Flensborg EW. The prognosis of bronchial asthma arising in infancy after the nonspecific treatment hitherto applied. Acta Paediatr Scand 1945; $33: 4-23$.

- Peckham C, Butler N. A national study of asthma in childhood. $\mathcal{F}$ Epidemiol Community Health 1978;32:79-85.

${ }^{5}$ Mitchell RG, Dawson B. Educational and social characteristics of children with asthma. Arch Dis Child 1973;48:467-71.

${ }^{6}$ Graham PJ, Rutter ML, Yule W, Pless IB. Childhood asthma: a psychosomatic disorder? Some epidemiological considerations. British fournal of Preventive Medicine 1967;21:78-85.

' Rawls DJ, Rawls JR, Harrison CW. An investigation of six to eleven yearold children with allergic disorders. F Consult Clin Psychol 1971 ;36:260-4.

${ }^{8}$ Burrows B, Lebowitz MD, Knudson RJ. Epidemiologic evidence that childhood problems predispose to airways disease in the adult (an asso- $\underline{\underline{\sigma}}$ ciation between adult and paediatric respiratory disorders). Pediatr Res $1977 ; 11: 218-20$.

${ }^{9}$ Holland WW, Halil T, Bennett AE, Elliott A. Factors influencing the onset of chronic respiratory disease. Br Med $\mathcal{F} 1969$;ii:205-8.

${ }^{10}$ Colley JRT, Douglas JWB, Reid DD. Respiratory disease in young adults : $\widehat{\Omega}$ influences of early childhood, lower respiratory tract illness, social class, air pollution, and smoking. Br Med f 1973;iii:195-8.

$"$ Barter CE, Campbell AH, Tandon MK. Factors affecting the decline in $\mathrm{FEV}_{1}$ in chronic bronchitis. Aust NZ F Med 1974;4:339-45.

12 Barter CE, Campbell AH. Relationship of constitutional factors and $\prod_{0}$ cigarette smoking to decrease in 1-second forced expiratory volume. $\mathrm{Am}$.. Rev Respir Dis 1976;113:305-14.

13 Williams HE, McNicol KN. Prevalence, natural history and relationship $\stackrel{\vec{\sim}}{+}$ of wheezy bronchitis and asthma in children. An epidemiological study. Br Med F 1969 ;iv:321-5.

14 Martin AJ, McLennan L, Landau LI, Phelan PD. The natural history of $\frac{\bar{\sigma}}{\overline{\mathrm{D}}}$ childhood asthma to adult life. $B r$ Med f 1980;280:1397-400.

15 Silverman M, Anderson SD. Standardisation of exercise tests in asthmatic $\stackrel{\mathbb{Q}}{\mathbb{Q}}$ children. Arch Dis Child 1972;47:882-9.

16 Martin AJ, Landau LI, Phelan PD. Lung function in young adults who ڤึ had asthma in childhood. Am Rev Respir Dis 1980;122:609-16.

17 Medical Research Council Committee on the Aetiology of Chronic Bronchitis. Definition and classification of chronic bronchitis for clinical $\overrightarrow{\vec{\omega}}$ and epidemiological purposes. Lancet 1965; ; :775-9.

${ }^{18}$ Simpson WT. Initial studies on the human pharmacology of salbutamol. Postgrad Med F 1971;47, suppl:35-8.

19 McNicol KN, Williams HE, Allan J, McAndrew I. Spectrum of asthma in children-III, psychological and social components. Br Med $\mathcal{F} 1973 ; \underset{\perp}{\infty}$ iv : $16-20$.

20 Bieman CW, Kawabori I, Pierson WE. Incidence of exercise induced $\omega$ asthma in children. Pediatrics $1975 ; 56$, suppl:847-50.

21 Woolcock AJ, Leeder SR, Peat JK, Blackburn SRB. The influence of lower $\omega$ respiratory illness in infancy and childhood and subsequent cigarette $\mathscr{O}$ smoking on lung function in Sydney school children. Am Rev Respir Dis $1979 ; 120: 5-14$

22 Kuperman AS, Riker JB. The variable effect of smoking on pulmonary or function. Chest 1973;63:655-60.

${ }^{23}$ Burrows B, Knudson RJ, Cline MG, Lebowitz MD. Quantitative re- $\frac{\mathbb{D}}{O}$ lationships between cigarette smoking and ventilatory function. Am Rev Respir Dis 1977;115:195-205.

24 Sanerkin NG. Terminology and classification of 'bronchial asthma' and 'chronic bronchitis': a reappraisal and redefinition. Ann Allergy 1971; $\vec{\bullet}$ 29:187-93.

\title{
Rubella screening and immunisation of schoolgirls: results six to seven years after vaccination
}

\author{
HELEN ZEALLEY， ELIZABETH EDMOND
}

\begin{abstract}
A long-term follow-up study was carried out of girls given RA27/3 or Cendehill rubella vaccine in their 13th14th year compared with a group of girls who had been found to be naturally immune at that age. $A$ high proportion of the girls in all groups had persistent rubella antibody six to seven years after inclusion in the study, although some of these would have been considered to be susceptible to rubella by methods currently in use for screening for rubella antibody.

Great care should be taken in interpreting the efficiency of the schoolgirl immunisation policy in the United Kingdom; women in their childbearing years who may
\end{abstract}

\section{Lothian Health Board}

HELEN ZEALLEY, MD, FFCM, community medicine specialist

Bacteriology Department, University of Edinburgh, and Regional

Virus Laboratory, City Hospital, Edinburgh

ELIZABETH EDMOND, MB, FRCPATH, senior lecturer have received vaccine but are found by a screening test $\frac{\delta}{2}$ to be seronegative should be retested by a more sensitive procedure before a final report is made.

\section{Introduction}

The aim of rubella vaccination policies in most European countries is to ensure that all women of childbearing age are $\omega$ immune to rubella. In practice this usually results in the offer of vaccine to all girls between their 11 th and 14th birthdays in $\stackrel{0}{=}$ Britain. To be effective in reducing the incidence of congenital $\stackrel{\Phi}{\oplus}$ rubella vaccine-induced immunity must persist throughout the reproductive period. We report here the results of a follow-up 0 study of immunity in schoolgirls who had been vaccinated and $\stackrel{\mathbb{D}}{\mathbb{D}}$ controls.

\section{Study group and procedure}

An immunisation programme aimed at Edinburgh schoolgirls in their 13-14th years was reported in $1974 . .^{1}$ All girls were screened for 